\title{
Experiential community pharmacy training: Assessment of students' perceptions in the United Arab Emirates
}

\author{
Munther S Alnajjar ${ }^{1,2}$ (iD) \& Alaa A Mohammed ${ }^{3}$ \\ ${ }^{1}$ Al-Ahliyya Amman University, Jordan $\quad{ }^{2}$ Al Ain University, United Arab Emirates $\quad{ }^{3}$ Mediclinic Al Jowhara Hospital, United Arab Emirates
}

\section{Keywords \\ Community Pharmacy \\ Community Training \\ Experiential Learning \\ Pharmacy}

\section{Correspondence}

Munther S Alnajjar

Assistant Professor of Clinical Pharmacy

Al-Ahliyya Amman University

Amman

Jordan

P. O. Box 19328, Amman, Jordan malnajjar01@qub.ac.uk

\begin{abstract}
Introduction: Community pharmacy settings provide places for promoting the effective and safe use of medicines all over the world. This study explored pharmacy students' perceptions of the barriers they had faced during their community pharmacy training as well as the factors affecting the training process outcome and their satisfaction with the training programme. Methods: A cross-sectional study was conducted among pharmacy students who had received their training in community settings and studied at academic institutions across the United Arab Emirates (UAE). A well-designed and validated questionnaire was employed. Logistic regression analyses were used to identify independent predictors of the students' satisfaction with their training experience. Results: A total of 250 (83.3\%) pharmacy students responded to the questionnaire. The results showed that the students were satisfied with their training experiences. However, they faced some barriers, such as not being able to respond to drug information inquiries from patients and/or interact with other healthcare providers and/or patients. Additionally, these factors were identified as independent predictors of the students' satisfaction with the training programme - that is, having a BSc. in Pharmacy as an academic major $(p=0.001)$, a student being in his/her fourth year of study $(p=0.003)$, increasing the average number of prescriptions per day at the pharmacy site $(p=0.004)$, having used prescription software at the pharmacy site $(p=0.049)$, and increasing the number of pharmacy preceptors in the pharmacy site per day $(p=0.002)$. Conclusion: This study confirmed that a training programme will help equip pharmacy students with the required knowledge and skills to practice the pharmacy profession effectively. However, the trainees reported barriers and problems that they had faced throughout their training.
\end{abstract}

\section{Introduction}

Pharmacy students are considered the foundation of the future of healthcare practitioners (Basak et al., 2009) Previously, the duty of pharmacists only involved providing traditional health-care services with relatively high quality with regard to dispensary duties and responsibilities. Nowadays, however, pharmacists act more specifically as healthcare promoters and providers, guidance counsellors, patient educators, pharmaceutical marketing officers, and the most powerful links between patients and other healthcare providers (Basak et al., 2009; Hattingh et al., 2009; Toklu \& Hussain, 2013; El Hajj et al., 2014; Baral et al., 2019). To be trusted sources of information for patients and other healthcare providers, pharmacists must be well trained and know how to get the most recent and reliable information related to the field of pharmacy from a trusted source (Basak et al., 2009; El Hajj et al., 2014; Baral et al., 2019; Almetwazi et al., 2020). 
Recently, the World Health Organisation (WHO) has added an important concept to the pharmacist's role, which is called rational drug use (RDU). This concept means using appropriate medicines based on the patient's clinical needs in a dose that is determined individually based on his/her own requirements, to be used for a specific period and with the lowest cost for the patient and his/her community (El Hajj et al., 2014; Baral et al., 2019; Almetwazi et al., 2020). To promote RDU, pharmacists need to be trained on the five rights of medication administration: the right patient, the right time, the right dose, the right route, and the right medication (WHO, 2007; Glayee et al., 2018). The patients' rights also include their right to know about their medical status and case development (WHO, 2007).

In Canada, the pharmacy profession finds itself in the midst of transformational change (Kassam, 2006; Hall et al., 2012). Its rules and regulations have been expanded, and the scope of pharmacy practice has also been widened (Kassam, 2006; Hall et al., 2012). New drug distribution methods and technologies in both hospital and community settings lead to opportunities for pharmacists to deviate from their traditional and routine roles in the drug-dispensing system (Hall et al., 2012).

As the life cycle always goes forwards and never backwards, the pharmacy profession also looks to develop in a way that allows pharmacists to play a major role as healthcare providers. This is why most developing countries employ experiential learning programmes called pharmacy internship programmes (Brown et al., 2009).

An experiential internship programme is structured in a professional way and helps pharmacy students practice what they have learnt from pharmacy school and apply it in real pharmacy settings. Most developed countries build their pharmacy internship programmes as introductions to pharmacy practice during the students' first three years of study (usually in community pharmacy settings), followed by advanced pharmacy practical experience during their last year of study; usually in both community pharmacy and hospital settings. (Brown et al., 2009; El Hajj et al., 2014; Gelayee et al., 2018; Baral et al., 2019; Almetwazi et al., 2020). This structure usually helps students apply the skills, attitudes, and knowledge they have developed in classroom and laboratory settings (Radigan, 2009; Al-Haidari \& Al-Jazairi, 2010; Al-Qadheeb et al., 2010; Avalere Health, 2014; McElhaney \& Weber, 2014; O'Sullivan et al., 2017; El Hajj et al., 2014; Baral et al., 2019; Almetwazi et al., 2020).

In developing countries, most universities have started making their pharmacy academic curricula patient- oriented rather than product oriented as the role of pharmacists previously involved only selling and dispensing medications; now they play an active role in medication safety (Stewart et al., 2011). One of the main targets of academic curriculum development is to produce competent healthcare providers in a patient-oriented pharmacy practice who can shift the role of the pharmacy profession from one that is product based to one that is patient care based (Robles, 2009).

The community pharmacists are positioned as the most accessible healthcare professionals. Their role has evolved and expanded to provide a variety of health services, which gives them more opportunities to make a substantial impact on the people they serve (Adams \& Blouin, 2017). The communities of clinical practice represent major sites for clinical curriculum delivery, where the clinical students can learn not only clinical skills but also how to be health professionals (Egen \& Jaye, 2009; O'Sullivan et al., 2017).

The Australian internship programme mainly depends on the pharmacists' ability and willingness to perform supervisory roles along with their other tasks (Stupans et al., 2011). In the Philippines, a training programme is considered a mandatory part of an academic curriculum in pharmacy education as it helps students experience actual practice in hospital, community, industrial, or manufacturing pharmacy settings (Carrido et al., 2016).

In the United Arab Emirates (UAE), the Department of Health (DOH) developed an experiential training programme that allows pharmacy students to acquire their internship only in specific settings where they are well prepared to deliver needed information and experience to society $(\mathrm{DOH}, 2018)$. The $\mathrm{DOH}$ believes that training sites play an important role in implementing the standards that pharmacists need to meet throughout their internship, which is why they put in place specific terms for pharmacies to be licensed and approved to accept trainees (DOH, 2018). The increasing number of pharmacy school students creates numerous challenges because of the corresponding increase in the number of pharmacists and training sites needed to provide highquality educational experiences to produce competent graduates (Rodger et al., 2008).

During their internships, students may face barriers and difficulties that could affect how they acquire information and skills. Some of these include the supervisor's workload, communication barriers, a lack of support from the pharmacy team, pharmacy space, and student engagement (Australian Government Department of Health and Ageing, 2008; El Hajj et al., 2014; Baral et al., 2019; Almetwazi et al., 2020). 
Moreover, among the main deficiencies involved in the academic curriculum is the scarceness of qualified professionals who are competent in community pharmacy and it's training requirements, methodologies, main fields, as well as the internship program outcomes. The reason may be that such areas are mainly taught by underqualified academics with limited past experience in community pharmacy (El Hajj et al., 2014; Carrido et al., 2016; Baral et al., 2019; Almetwazi et al., 2020). The lack of such knowledge results in a gap between what students learn at school and what they do in practice; moreover, it leads to a loss of interest in community pharmacy practice (El Hajj et al., 2014; Carrido et al., 2016; Baral et al., 2019; Almetwazi et al., 2020). Another barrier that students face is their preceptors in the training site as these preceptors may not give them the required training time, or discuss training manuals, nor follow up on their progress throughout their internship (Marriott et al., 2005; Owen et al., 2011; Mak et al., 2013; Fejzic et al., 2013; Carrido et al., 2016; Almetwazi et al., 2020).

Last but not least, all the studies conducted worldwide prove that a pharmacy internship programme plays an important role in the structure of a pharmacist's skills and knowledge for future practice (Al-Arifi, 2009; Udeogaranya et al., 2009; Rahim \& Nesar, 2012; El Hajj et al., 2014; Tsega et al., 2015; Carrido et al., 2016; Baral et al., 2019; Almetwazi et al., 2020). Throughout their internships, students could face barriers that have not previously been discussed in any study based in the UAE, which is why this research has been conducted - to identify the barriers that students face during their internships in the UAE.

\section{Methods}

\section{Aim of the study}

This study explored pharmacy students' perceptions and identification of barriers they face during their community pharmacy training as well as the factors that affect the outcome of the training process and their satisfaction with the programme.

\section{Study design and setting}

This quantitative cross-sectional study was conducted from September 2018 to March 2019. A purpose-designed questionnaire was distributed to pharmacy students at several academic institutions across the UAE: (i) College of Pharmacy, Al Ain University of Science and Technology
(AAU); (ii) College of Pharmacy, University of Sharjah; (iii) College of Pharmacy, Dubai Medical College; (iv) College of Pharmacy, Fatima College of Health Sciences; and (v) other universities. The questionnaire was uploaded to Google Drive and distributed online to all colleges of pharmacy throughout the UAE. The entire survey took about ten minutes to complete.

\section{Ethical consideration}

Participation in the study was voluntary and did not pose any risk to the respondents. A written consent form was provided to explain the purpose of the study, and the information that the participating students gave would remain confidential and be used for research purposes only. The participants were asked to read, comprehend, and sign the informed consent form prior to answering the questionnaire. This work was conducted in partial fulfilment of the requirements for the Master's Degree in Clinical Pharmacy at the College of Pharmacy in AAU. The research plan was reviewed and approved by the College of Pharmacy Postgraduate Studies Committee in AAU.

\section{Study questionnaire}

The questionnaire was produced by the authors and employed for this study. The contents of the questionnaire were adapted from the existing literature and amended accordingly (Young et al., 2014; Bhagavathula et al., 2017). The retrieved statements from the initial questionnaire were reviewed and amended substantially in a way that reflected pharmacy education and practice in the UAE. The final version of the questionnaire highlighted the main points that could affect the students' training process and the barriers that they could face in the pharmacy training programme. The survey included five parts: the pharmacy students' general information and demographic data; their perception towards training site preceptors; their perception towards training sites; their opportunities during their experiential training; and their feedback regarding the outcome of their training. A 5-point Likert scale was used to score the items: 'Strongly Disagree', 'Disagree', 'Neutral', 'Agree', and 'Strongly Agree'.

\section{Development of the study instrument and validity assessment}

The face validity of the amended questionnaire was assessed through peer review by three relevant experts (Ph.D. holders) with substantial experience in survey design and development. In October 2018, the 
questionnaire was piloted by asking 15 pharmacy students in the UAE to comment on the clarity and simplicity of the items. All the comments from the experts and participating students were considered when developing the final version of the questionnaire.

\section{Sample size estimation}

The sample size was calculated using an online sample size calculator at a $95 \%$ confidence level and a $5 \%$ margin of error. Based on the calculation results, a convenient sample composed of 300 students was used to examine the students' responses to the pharmacy training programme.

\section{Study inclusion and exclusion criteria}

Inclusion criteria

- Community pharmacy trainee/intern students

- Pharmacy trainees in the UAE

\section{Exclusion criteria}

- Students who got their training in hospital settings

- Licensed pharmacists

\section{Statistical analyses}

Simple descriptive statistics was used to calculate the frequency counts and percentages with regard to the respondents' demographics and the most common barriers and difficulties they had faced during pharmacy training using a Likert scale. To identify the individual relationships between the students' demographics (and baseline characteristics) and the variables and levels of the students' agreements with regard to their training experiences, a univariate analysis was performed. Pearson's chi-square test was used with categorical variables, and the independent $t$-test was used with continuous variables. Following this, a backward logistic regression analysis was performed (all variables with a $p$-value $\leq 0.25$ in the univariate analysis were included) to identify significant independent predictors of the students' satisfaction with the training programme. The odds ratio approach was used to express the extent of the increased or decreased likelihood of being satisfied with the pharmacy training (with $p \leq 0.05$ deemed statistically significant). The collected data from the survey were encoded using Microsoft Office Excel 2013. All the statistical procedures were performed using the Statistical Package for Social Sciences, Windows version 20.0.

\section{Results}

The survey was distributed to 300 pharmacy students throughout the UAE. Only 250 trainees completed the questionnaire, with a response rate of $83.3 \%$. In this study, the questionnaire was divided into five parts, as follows.

Table I: General information and demographic data of pharmacy students

\begin{tabular}{|c|c|c|c|}
\hline $\begin{array}{l}\text { General information } \\
\text { and demographic } \\
\text { data }\end{array}$ & $\begin{array}{l}\text { Respondents } \\
(\mathrm{N}=\mathbf{2 5 0})\end{array}$ & Frequency & $\%$ \\
\hline \multirow[t]{5}{*}{ Current university } & $\begin{array}{l}\text { Al Ain University of } \\
\text { Science and Technology }\end{array}$ & 79 & 31.6 \\
\hline & Al Sharjah University & 61 & 24.4 \\
\hline & Dubai Medical College & 36 & 14.4 \\
\hline & Fatima College & 35 & 14.0 \\
\hline & Others & 39 & 15.6 \\
\hline \multirow[t]{2}{*}{ Gender } & Female & 151 & 60.4 \\
\hline & Male & 99 & 39.6 \\
\hline \multirow[t]{2}{*}{ Academic major } & BSc. Pharmacy & 209 & 83.6 \\
\hline & Pharm.D. & 41 & 16.4 \\
\hline \multirow[t]{3}{*}{ Year of study } & 2nd year & 34 & 13.6 \\
\hline & 3rd year & 24 & 9.6 \\
\hline & 4th year & 192 & 76.8 \\
\hline \multirow[t]{4}{*}{ Residential area } & Abu Dhabi & 31 & 12.4 \\
\hline & Al Ain & 94 & 37.6 \\
\hline & Dubai & 43 & 17.2 \\
\hline & Sharjah & 82 & 32.8 \\
\hline \multirow[t]{2}{*}{ Last training site } & Independent pharmacy & 149 & 59.6 \\
\hline & Chain pharmacy & 101 & 40.4 \\
\hline \multirow{6}{*}{$\begin{array}{l}\text { Average number } \\
\text { of prescriptions } \\
\text { dispensed/day at } \\
\text { practice site }\end{array}$} & Less than 50 & 30 & 12.0 \\
\hline & 50-99 & 29 & 11.6 \\
\hline & $100-149$ & 25 & 10.0 \\
\hline & 150-199 & 26 & 10.4 \\
\hline & $200-249$ & 64 & 25.6 \\
\hline & More than 250 & 76 & 30.4 \\
\hline \multirow{2}{*}{$\begin{array}{l}\text { Prescription } \\
\text { software available }\end{array}$} & No & 49 & 19.6 \\
\hline & Yes & 201 & 80.4 \\
\hline \multirow{5}{*}{$\begin{array}{l}\text { Number of active } \\
\text { pharmacy preceptors } \\
\text { available at the } \\
\text { time of training }\end{array}$} & 1 pharmacist & 19 & 7.6 \\
\hline & 2 pharmacists & 39 & 15.6 \\
\hline & 3 pharmacists & 28 & 11.2 \\
\hline & 4 pharmacists & 47 & 18.8 \\
\hline & 5 pharmacists or more & 117 & 46.8 \\
\hline
\end{tabular}




\section{Part I: General information and demographic data of pharmacy students}

Of the total surveyed students, $60.4 \%$ were female $(n=151)$, while $39.6 \%$ were male $(n=99)$. About $31.6 \%$ $(n=79)$ of the sample were still studying and/or had graduated from AAU, followed by respondents from $\mathrm{Al}$ Sharjah University, with a percentage of $24.4 \%(n=61)$. Participants from other universities made up $15.6 \%(n=39)$ of the sample, while those from Dubai Medical College and Fatima College each made up around $14.0 \%$. Most of the respondents, about $83.6 \%(n=209)$, were enrolled in the BSc pharmacy programme, while the rest, about $16.4 \%(n=41)$, were Doctor of Pharmacy (Pharm.D.) students.

\section{Part II: Perception towards training site preceptors}

Preceptors' attitude towards students

Of the total students, $40.8 \%$ gave positive responses to the way that their preceptors had encouraged them to be involved in some pharmacy tasks. Moreover, $52.8 \%$ of the students responded that the pharmacy preceptors had supported them in the learning process and in gaining more pharmaceutical knowledge.

\section{Preceptors' engagement in the training process}

Around $48.0 \%$ of the students were satisfied with their pharmacy preceptors as they had allowed them to apply their training in a patient-oriented manner. About 51.2\% of those responded that the preceptors had given them the chance to interact with other members of the healthcare team.

\section{Preceptors' characteristics}

Around $44.8 \%$ the students stated that their pharmacy preceptors had performed as role models in the pharmacy practice. About $49.6 \%$ of these students believed that their pharmacy preceptors possessed strong interpersonal skills, which had a positive effect on the students during their training programme.

\section{Part III: Perception towards training sites (community pharmacies)}

\section{General characteristics of the training sites}

Around $50.0 \%$ of the students said that their training sites were equipped with the needed drug information resources. Moreover, $44.4 \%$ of them mentioned that those resources were easily accessible. About $45.2 \%$ of the trainees gave positive responses regarding their training sites, stating that they contained adequate volumes of over-the-counter (OTC) medications.

\section{Suitability of training sites for the training process}

Of the total students, $56.4 \%$ responded that their training sites had the adequate patient populations needed to meet the learning objectives set for training.

\section{Part IV: Pharmacy students' opportunities during their training experience}

Only $38.0 \%$ of all the surveyed students said that they were able to interview patients, and about $32.4 \%$ could and were allowed to create electronic profiles for the patients, while $46.0 \%$ were allowed to assess the patients' information. Moreover, about $39.2 \%$ of the students were free to interact with other health-care professionals. In addition, less than half $(40.8 \%)$ of them responded that they were able to counsel the patients on their prescriptions (about 39.6\% for OTC medications).

\section{Part V: Pharmacy student feedback on the outcomes of their training experience}

About $44.0 \%$ of all the trainees agreed that their internship experience had increased their involvement in the pharmacy profession. More than half of them, almost $55.6 \%$, mentioned that the training experience had helped them develop their lifelong learning skills and pharmaceutical knowledge.

\section{Univariate analysis of student-related factors affecting students' satisfaction with the training process}

The results of the univariate analysis (Table II) showed individual relationships (with $p$-values $\leq 0.25$ ) between the level of agreement with regard to the influence of the training experience (on involvement in the pharmacy profession) and current university, academic major, year of study, residential area, average number of prescriptions dispensed per day, available prescription software, and number of active pharmacy preceptors.

\section{Multivariate analysis of student-related factors affecting students' satisfaction with the training process}

All the variables that had reached the selected significance level (i.e. $p \leq 0.25$ ) in the univariate analysis were included as explanatory variables in backward multivariable logistic regression modelling. The outcome variable in this model was the level of the students' agreements with regard to their training experiences ('Yes'/'No').

The developed multivariate model (Table III) highlights the variables that were independent predictors of the positive impact of the training experience on the students' level of 
Table II: Univariate analyses of variables linked to students' satisfaction with training programme

\begin{tabular}{|c|c|c|c|c|}
\hline Variable & Sub-group & Disagree $(N=46)$ & Agree(N = 179) & $p$-value ${ }^{*}$ \\
\hline \multirow[t]{2}{*}{ Gender } & Male & $21(45.7 \%)$ & $72(40.2 \%)$ & 0.307 \\
\hline & Female & $25(54.3 \%)$ & 107 (59.8\%) & \\
\hline \multirow[t]{5}{*}{ Current university } & Al Ain University & $10(21.7 \%)$ & $58(32.4 \%)$ & 0.036 \\
\hline & Al Sharjah University & $13(28.3 \%$ & $46(25.7 \%)$ & \\
\hline & Dubai Medical College & $3(6.5 \%)$ & 32 (17.9\%) & \\
\hline & Fatima College & $9(19.6 \%)$ & $24(13.4 \%)$ & \\
\hline & Others & $11(23.9 \%)$ & $19(10.6 \%)$ & \\
\hline \multirow[t]{2}{*}{ Academic major } & BSc .Pharmacy & $20(43.5 \%)$ & $168(93.3)$ & 0.001 \\
\hline & Pharm.D. & $26(56.5 \%)$ & $11(6.1 \%)$ & \\
\hline \multirow[t]{3}{*}{ Year of study } & 2nd year & $15(32.6 \%)$ & $11(6.1 \%)$ & 0.001 \\
\hline & 3rd year & $15(32.6 \%)$ & $7(3.9 \%)$ & \\
\hline & 4th year & $16(34.8 \%)$ & $161(89.9 \%)$ & \\
\hline \multirow[t]{4}{*}{ Residential area } & Abu Dhabi & $10(21.7 \%)$ & $18(10.1 \%)$ & 0.001 \\
\hline & Al Ain & $17(37.0 \%)$ & $62(34.6 \%)$ & \\
\hline & Dubai & $15(32.6 \%)$ & $24(13.4 \%)$ & \\
\hline & Sharjah & $4(8.7 \%)$ & 75 (41.9\%) & \\
\hline \multirow[t]{2}{*}{ Last training site } & Independent pharmacy & $25(54.3 \%)$ & $112(62.2 \%)$ & 0.197 \\
\hline & Chain pharmacy & $21(45.7 \%)$ & 67 (37.4\%) & \\
\hline \multirow[t]{6}{*}{ Average number of prescriptions dispensed per day } & Less than 50 & $11(23.9 \%)$ & $13(7.3 \%)$ & 0.001 \\
\hline & $50-99$ & $14(30.4 \%)$ & $5(2.8 \%)$ & \\
\hline & $100-149$ & $6(13.0 \%)$ & $13(7.3 \%)$ & \\
\hline & 150-199 & $7(15.2 \%)$ & $17(9.5 \%)$ & \\
\hline & $200-249$ & $4(8.7 \%)$ & $59(33.0 \%)$ & \\
\hline & 250 and more & $4(8.7 \%)$ & $72(40.2 \%)$ & \\
\hline \multirow[t]{2}{*}{ Prescription software } & No & $26(56.5 \%)$ & $17(9.5 \%)$ & 0.001 \\
\hline & Yes & $20(43.5 \%)$ & $162(90.5 \%)$ & \\
\hline \multirow[t]{5}{*}{ Number of active pharmacy preceptors } & 1 pharmacist & $7(15.2 \%)$ & $6(3.4 \%)$ & 0.001 \\
\hline & 2 pharmacists & $15(32.6 \%)$ & $15(8.4 \%)$ & \\
\hline & 3 pharmacists & $12(26.1 \%)$ & $13(7.3 \%)$ & \\
\hline & 4 pharmacists & $10(21.7 \%)$ & 33 (18.9\%) & \\
\hline & 5 pharmacists & $2(4.3 \%)$ & $112(62.6 \%)$ & \\
\hline
\end{tabular}

"variables with $p \leq 0.25$ were presented in bold

Table III: Output of multivariate analyses regarding variables that were independently linked to increased students' satisfaction with training programme

\begin{tabular}{|c|c|c|c|c|}
\hline Variable & Sub-group & $p$-value* & Odds ratio (OR) & Confidence interval ${ }^{\#}$ \\
\hline \multirow[t]{2}{*}{ Academic major } & BSc. Pharmacy & & 1 & \\
\hline & Pharm.D. & 0.001 & 0.04 & $0.01-0.26$ \\
\hline \multirow[t]{3}{*}{ Year of study } & 2nd year & & 1 & \\
\hline & $3 r d$ year & 0.337 & 3.00 & $0.32-28.25$ \\
\hline & 4th year & 0.003 & 36.03 & $3.39-383.49$ \\
\hline \multirow[t]{6}{*}{ Number of prescriptions } & Less than 50 & & 1 & \\
\hline & $50-99$ & 0.004 & 0.02 & $0.001-0.27$ \\
\hline & $100-149$ & 0.279 & 3.40 & $0.37-31.23$ \\
\hline & 150-199 & 0.812 & 0.75 & $0.07-8.11$ \\
\hline & $200-250$ & 0.734 & 1.55 & $0.12-19.66$ \\
\hline & More than 250 & 0.778 & 0.70 & $0.06-8.32$ \\
\hline \multirow[t]{2}{*}{ Prescription software available } & No & & 1 & \\
\hline & Yes & 0.049 & 4.75 & $0.99-22.849$ \\
\hline \multirow[t]{5}{*}{ Number of preceptors available } & 1 pharmacist & & 1 & \\
\hline & 2 pharmacists & 0.520 & 18.56 & $1.06-326.33$ \\
\hline & 3 pharmacists & 0.430 & 3.00 & $0.20-45.89$ \\
\hline & 4 pharmacists & 0.020 & 48.40 & $1.84-1,271.40$ \\
\hline & 5 pharmacists & 0.002 & 375.52 & $8.05-17,523.05$ \\
\hline
\end{tabular}

"All variables with $p \leq 0.05$ were presented in bold

$\#=95 \%$ confidence interval 
involvement in the pharmacy profession - that is, being enrolled in a Bachelor of Science (BSc.) programme, a student being in his/her fourth year of study, increasing the average number of prescriptions dispensed per day at the pharmacy site, having used prescription software at the pharmacy site, and increasing the number of pharmacy preceptors in the pharmacy site per day.

The analysis shows that being a Pharm.D. student resulted in a $96 \%$ decrease in the odds of being satisfied with the training experience on the level of involvement in the pharmacy profession when compared with having a BSc. degree in pharmacy ( $\mathrm{Cl} 95 \% 0.01-0.26, p=0.001)$. Being a fourth-year pharmacy student increased the odds of being satisfied with the training experience on the rate of integration into the pharmacy profession by 36.03 -fold compared with being a second-year student (Cl 95\% 3.39383.49, $p=0.003$ ).

The odds of satisfaction with the influence of training decreased by $98 \%$ amongst students who had been assigned to practice sites where an average number of 50-99 prescriptions were dispensed per day compared with those who had been assigned to practice sites dispensing fewer than 50 prescriptions per day (Cl 95\% $0.001-0.27, p=0.004)$. The presence of software in the practice site increased the involvement of the students 4.75-fold compared with no software used by the trainees in the practice site ( $\mathrm{Cl} 95 \%$ 0.99-22.849, $p=0.049$ ).

The odds of students who had had training with four pharmacy preceptors being satisfied were 48.4 times greater than the odds of those who had been exposed to pharmacy training with one training preceptor ( $\mathrm{Cl} 95 \%$ 1.84-1,271.40, $p=0.020$ ). Being supervised by five pharmacy preceptors increased the odds of being satisfied with the outcome of the training process by a factor of 375.52 compared with undergoing training with only one pharmacy preceptor (Cl 95\% 8.05-17,523.05.40, $p=0.002$ ).

\section{Discussion}

\section{Students' perceptions of the barriers that affect community pharmacy training programmes}

This is the first nationwide study to assess undergraduate pharmacy students' attitudes and perceived barriers towards the provision of pharmaceutical care services in community pharmacy setting in the UAE. The authors' results showed that the students had favourable attitudes toward their training experiences. The students were satisfied with their experience regarding gained skills, knowledge, and attitudes. This finding is consistent with studies conducted in several countries including Qatar, Nepal, Ethiopia, Nigeria, Pakistan, Saudi Arabia, Kuwait, Philippine and Australia (Al-Arifi, 2009; Udeogaranya et al., 2009; Rahim and Nesar, 2012; El Hajj et al., 2014; Tsega et al., 2015; Carrido et al., 2016; Baral et al., 2019; Almetwazi et al., 2020).

Regarding the students' perception towards the pharmacy preceptors, $(48.8 \%)$ and $(49.6 \%)$ of students agreed that the pharmacy preceptors were role models for pharmacy practice and they had strong interpersonal skills. These results are similar to those have been reported in studies for community pharmacy carried out in Saudi Arabia (with 49.0\%) and Qatar (with 51.0\%) (El Hajj et al., 2014; Almetwazi et al., 2020). Preceptors criteria of excellence have been identified by the Academic Practice Partnership Initiative of the American Association at College of Pharmacy (Boyle et al., 2009). In the present study, about $40.8 \%$ of the respondents stated that their preceptors had encouraged them and supported them throughout their training period. Their preceptors should always support them, be willing to understand their needs as students, and try to fill the gaps between theoretical and practical points of view as the quality of pharmacy education mainly depends on the preceptors' quality and effectiveness (Wallman, 2010). When participants in the current study were asked whether the preceptors allowed them to actively perform their training in a patientoriented manner and whether preceptors gave them the opportunity to interact with other healthcare personnel on the team, about half of students strongly agreed with these statements. This result is much lower than those demonstrated in two relevant studies conducted in Saudi Arabia (67.0\%) and Canada (93.0\%; Kassam, 2006; Almetwazi et al., 2020). The possible explanation is that learning activities descriptions provided were not clear enough for the allocated pharmacy preceptors in this study's community pharmacies.

Another positive factor is the training site itself. The students in this study gave positive feedback regarding their training sites. The students shared that appropriate and easily accessible drug information resources, an adequate volume of 'over the counter' (OTC) medications, and a prescription volume adequate for effective learning are all positive factors (at rates of almost $50 \%$ and above). Similar results were showed in previous study done in Qatar and Nepal (El Hajj et al., 2014; Baral et al., 2019). Undertaking an approach toward providing the pharmacists with access to drug information resources will guide them to adequately exercise the provision of pharmaceutical care in community pharmacy setting (Baral et al., 2019). 
Previous studies have reported several major barriers in achievement of diverse pharmaceutical care, these include lack of access to patient interaction and workplace for patient counselling; lack of time; inadequate drug information sources; insufficient professional skills and poor image of the pharmacists; lack of pharmacists' selfconfidence; inadequate clinical knowledge and communication skills (May, 1993; McDonough et al., 1998; Marriott et al., 2005; Ngorsuraches \& Li, 2006; Uema et al., 2008; Fang et al., 2011; El Hajj et al., 2014; Carrido et al., 2016; Baral et al., 2019; Almetwazi et al., 2020).

The results of the current study demonstrated the lack of access to patient medical records in pharmacy and workplace settings for patient counselling (on their prescribing their medicines), as well as limited interaction with other healthcare professionals were the top perceived barriers for pharmaceutical care provision. Many previous studies highlighted the inability of pharmacy students to obtain clinical and laboratory data of patients as one of the perceived barriers to pharmaceutical care provision (Farris et al., 2005; Ngorsuraches \& Li, 2006; El Hajj et al., 2014; Baral, 2019). This emphasises the need for having patient medical records in the UAE community pharmacies to provide an opportunity for developing a scope of pharmaceutical care. The pharmacy students should be afforded the opportunity to offer pharmaceutical care directly to the actual patients under observation of allocated preceptors and should be engaged in the entire patient care process from assessment to follow-up monitoring (El Hajj et al., 2014; Carrido et al., 2016; Almewazi et al., 2020). The main target of these interactions is to teach students to develop an appreciation of their significant role as future pharmacists. (El Hajj et al., 2014; Almewazi et al., 2020). Additionally, the current results highlight the need to have pharmacy experiential training sites that are designed to prepare pharmacy students in the UAE for optimal pharmaceutical care practice. To improve learning environments, training skills must be improved to ensure optimum interaction with patients and healthcare providers, e.g. by providing students with training tasks (El Hajj et al., 2014; McElhaney \& Weber, 2014; Almetwazi et al., 2020).

\section{Multivariate analysis of student-related factors positively affecting students' satisfaction with training experiences}

By checking the variables that were independently associated with the influence of the training experience on the students' involvement in the pharmacy profession, the results showed that participating Pharm.D. students were less satisfied with their training experience compared with students enrolled in BSc. pharmacy programmes, as the Pharm.D. students were assumed to want hospital training and to be more involved in clinical practice. Further investigations are required to assess this finding.

Also, the results showed that the fourth-year students were more satisfied with the influence of the training and were more willing to acquire pharmaceutical knowledge throughout their training as they were almost done with the pharmaceutical academic curriculum, which yielded a positive outcome in their clinical internship. Another explanation is that most of the subjects delivered in early pharmacy education are taught by lecturers with limited exposure to community pharmacies. However, in previous study conducted to recognise the Qatar Pharmacy students' perceived barriers for pharmaceutical care provision, students who participated earlier in their professional years have higher positive attitudes toward pharmaceutical care (El Hajj et al., 2014).

Another important factor that affected the training process was the number of prescriptions dispensed per day in the practice site. A higher number of prescriptions was positively linked to the increased odds of satisfaction across the students regarding the training process. This could be due to the fact that some students may have interviewed higher numbers of patients during their training and were exposed to extensive pharmacy activities.

The presence of prescription software in the pharmacy was assumed to help students access the patient profiles more easily and check the history of dispensed medications and allergies. This software may have increased their satisfaction with the training process. This result has been reported in previous studies where pharmacy students had very small number of hardcopy drug information resources (El Hajj et al., 2014; Baral et al., 2019). Additionally, in a study performed in Saudi Arabia to assess the pharmacy students' satisfaction with pharmacy experiences of community pharmacy, the students reported they did not get all required information from their patients and relied only on the prescription provided. These training sites in Saudi Arabia were lacking electronic systems (Almetwazi et al., 2020). The results of the present study highlight the need to support the pharmacy students with all required tools to easily access patient's medical records through utilisation of electronic systems.

Last but not least, the results showed a positive relationship between the number of preceptors in the 
training site and the level of students' satisfaction with the pharmacy's activities, giving the preceptors more time to discuss the training manuals and to teach their students more concepts related to pharmacy practice. The results showed that pharmacies with five or more pharmacists have the highest odds ratio (OR) (375.52). These results are consistent with previous studies which showed that lower number of pharmacy preceptors was associated with less time to train pharmacy students, which reflected on their satisfaction level about their training experience outcomes. (Bell et al., 1998; Farris et al., 2005; Uema et al., 2008; Fang et al., 2011). In study conducted in 2014, a suggestion was provided to exempt pharmacy preceptors from performing the routine dispensing tasks, so they can have more time and attention for cognitive services (EI Hajj et al., 2014).

Overall, the above-mentioned variables were identified as independent predictors of the positive impact of the training experience on the level of the students' satisfaction with the training programme. Highlighting the barriers that pharmacy students face in their training programme will help improve such a programme in the UAE. This improvement can be achieved by creating training sessions for preceptors before sending any students for training so that these preceptors will know the points that their universities are looking to cover (Fejzic et al., 2013, El Hajj et al., 2014; Almetwazi et al., 2020)

Furthermore, these challenges could be solved through adequate site supervision at community pharmacies by qualified community pharmacists (El Hajj et al., 2014; Almetwazi et al., 2020). Countering these barriers to pharmacy students in community pharmacies requires a high-quality culture when choosing a community pharmacy as a potential site for internship (El Hajj et al., 2014; Baral et al., 2019). Moreover, to monitor the quality of the community pharmacy, documentation should be signed with the training site, and frequent auditing is required. The presence of a structured pharmacy practice guide for pharmacy students as well as an initial orientation session before starting the internship would also be helpful (Al-Haddad \& Hassali, 2010). Bond and Cone (2012) believe that the academic curriculum should not exclusively focus on pharmaceutical knowledge but should also provide students with the skills that they need to practice pharmacy in the future. They also believe that developing a programme that contains simulations of the patient environment will help students build up their confidence and develop their practical skills (Almetwazi et al., 2020). In order to improve the pharmacy experiential training experience and to prepare the students for community pharmacy practice, pharmacy practice simulation centres should be established by colleges of pharmacy in the UAE (Baral et al., 2019; Almetwazi et al., 2020). Hall and colleagues in 2011, published a paper that contained the main points in improving the training programme. Those points were as follows: the training programme should start within the early years of the academic curriculum and work in parallel with each other; the training programme should have enough period of rotation before students starts their training (Hall et al., 2012). The trainee should also play a role and take responsibility, especially throughout his/her training period (Hall et al., 2012). A study conducted in Australia in 2013 highlighted the need to improve communication skills among students, as the results showed that it was an important factor in developing the training outcomes (Fejzic et al., 2013; Almetwazi et al., 2020).

\section{Study strengths and limitations}

This is the first study in the UAE that discusses the barriers that pharmacy trainees face in their training programmes. However, one limitation was noted throughout this study: some students had difficulty recalling their training experiences as well as their feelings towards them.

\section{Conclusion}

This study confirms that training programmes will equip pharmacy students with the required knowledge and skills to practice the pharmacy profession efficiently. However, some students reported barriers and problems that they had faced throughout their training. The results show that the gained learning outcomes mainly revolved around the normal and routine pharmacist roles such as dispensing medicine and handling retail activities. The following factors were identified as independent predictors of the positive impact of the training experience on the students' level of involvement in the pharmacy profession: being a BSc. student; being in the fourth year of study; increasing the average number of prescriptions dispensed per day at the pharmacy site; having prescription software available at the practice site; and increasing the number of pharmacy preceptors in the pharmacy site per day. 


\section{Acknowledgements}

The authors would like to thank all the questionnaire participants in the UAE for their time and responses to this study.

\section{References}

Adams, M.L., \& Blouin, R.A. (2017). The role of the pharmacist in health care: Expanding and evolving. North Carolina Medical Journal, 78(3), 165-167. https://doi.org/10.18043/ncm.78.3.165

Al-Arifi, M.N. (2009). Pharmacy students' attitudes toward pharmaceutical care in Riyadh region Saudi Arabia. Pharmacy World \& Science, 31(6), 677-681. https://doi.org/10.1007/ $\underline{\text { s11096-009-9331-y }}$

Al-Haddad, M.M., \& Hassali, M.A. (2010). Challenges to pharmacy students training in community pharmacies. Archives of Pharmacy Practice, 1(1), 3-4

Al-Haidari, K.M., \& Al-Jazairi, A.S. (2010). Establishment of a national pharmacy practice residency programme in Saudi Arabia. American Journal of Health-System Pharmacy, 67(17), 1467-1537. https://doi.org/10.2146/ajhp090536

Almetwazi, M., Alhammad, A., Alhossan, A., Alturki, H., Aljawadi, M., \& Asiri, Y. (2020). Pharmacy students' satisfaction with Introductory Pharmacy Practice Experiences (IPPE) at community pharmacy: The case of Saudi Arabia. The Saudi Pharmaceutical Journal, 28(1), 68-73. https://doi.org/10.1016/i.jsps.2019.11.006

Al-Qadheeb, N., Alissa, D., Al-Jedai, A., Ajlan, A., \& Al-Jazairi, A. (2012). The first international residency program accredited by the American Society of Health-System Pharmacists. American Journal of Pharmaceutical Education, 76(10), 190. https://www.ajpe.org/ content/76/10/190

Australian Government Department of Health and Ageing. (2008). Analysis of secondary data to understand pharmacy workforce supply - Initial supply report, Canberra (online). Available at: http://6cpa.com.au/wp-content/uploads/Pharmacy-WorkforcePlanning-Initial-Supply-Report.pdf

Avalere Health. (2014). Exploring pharmacists' role in a changing healthcare environment (online). Available at: https:// www.nacds.org/pdfs/comm/2014/pharmacist-role.pdf

Baral, S.R., Parajuli, D.R., \& Shrestha, S. (2019). Undergraduate pharmacy students' attitudes and perceived barriers toward provision of pharmaceutical care: a multi-institutional study in Nepal. Integrated Pharmacy Research and Practice, 8, 47-59. https://doi.org/10.2147/IPRP.S203240

Basak, S., Vanmil, J., \& Sathynarayana. (2009). The changing roles of pharmacists in community pharmacies: Perception of reality in India. Pharmacy World and Science, 31(6), 612-620. https:// doi.org/10.1007/s11096-009-9307-y

Bell, H.., McElnay, J., Hughes, C., \& Woods. (1998). A quantitative investigation of the attitudes and opinion of community pharmacist to pharmaceutical care. Journal of the American Pharmacists Association, 15, 284-295
Bhagavathula, A.S., Bandari, D.K., Gogikar, S.K., Elnour, A.A., \& Shehab, A. (2017). Experiences and perceptions of pharmacy students on practical skills and education during clinical rotations in India. American Journal of Pharmaceutical Education, 81(6), 109. https://doi.org/10.5688/ajpe816109

Binos, R.S.R., Lara, K.P., Yu, A.H.C., \& Loquias, M.M. (2011). Perceptions of Pharmacy Students in Metro Manila towards their Preparedness to Provide Pharmaceutical Care. International Journal of Pharmacy Teaching \& Practices, 2(3),102-107

Bond, R., \& Cone, C. (2012). Improving student confidence in skill performance in a pharmaceutical care lab setting. Pharmacy Education, 12(1), 20-24

Brown, B., Skau, K., \& Wall, A. (2009). Learning across the curriculum: Connecting the pharmaceutical sciences to practice in the first professional year. American Journal of Pharmaceutical Education, 73(2), 36. https://doi.org/10.5688/aj730236

Carrido, D., Macaldo, A., Lorenzo, C., \& Loquias, M. (2016). Evaluation of community pharmacy internship program in the Philippines. Pharmacy Education, 16(1), 103-108

Department of Health (DOH). (2018). Pharmacy internship programme (online). Available at: https://www.doh.gov.ae

Egan, T., \& Jaye, C. (2009). Communities of clinical practice: The social organization of clinical learning. Journal for the Social Study of Health, Illness and Medicine, 13, 107-125. https://doi.org/ $\underline{10.1177 / 1363459308097363}$

El Hajj, M., Hammad, A., \& Afifi, H. (2014). Pharmacy students' attitudes toward pharmaceutical care in Qatar. Therapeutics and Clinical Risk Management, 10, 121-129. https://doi.org/10.2147/ TCRM.S56982

Fang, Y., Yang, S., Feng, B., Ni, Y., \& Zhang, K. (2011). Pharmacists' perception of pharmaceutical care in community pharmacy: a questionnaire survey in Northwest China. Health \& Social Care in the Community, 19(2),189-197. https://doi.org/10.1111/i. 1365-2524.2010.00959.x

Farris, K.B., Fernandez-Llimos, F., \& Benrimoj, S.I. (2005). Pharmaceutical care in community pharmacies: practice and research from around the world. Annals of Pharmacotherapy, 39(9),1539-1541. https://doi.org/10.1345/aph.1G049

Fejzic, J., Henderson, A., Nerida, A., \& Mey, A. (2013). Community pharmacy experiential placement: Comparison of preceptor and student perspectives in an Australian postgraduate pharmacy programme. Pharmacy Education, 13(1), 15-17

Gelayee, D.A., \& Mekonnen, G.B. (2018). Pharmacy students' provision of health promotion counseling services during a community pharmacy clerkship: a cross sectional study, Northwest Ethiopia. BMC Medical Education, 18(1), 95. https:// doi.org/10.1186/s12909-018-1216-0

Hall, K., Musing, E., Miller, D., \& Tisdale, J. (2012). Experiential training for pharmacy students: Time for a new approach. Canadian Journal of Hospital Pharmacy, 65(4), 285-378. https:// doi.org/10.4212/cjhp.v65i4.1159 
Hattingh, L., King, M., \& Smith N. (2009). An evaluation of the integration of standards and guidelines in community pharmacy practices. Pharmacy World Science, 31, 542-549. https://doi.org/ 10.1007/s11096-009-9309-9

Kassam, R. (2006). Students' and preceptors' experiences and perceptions of a newly developed community pharmacy pharmaceutical care clerkship. Pharmacy Education, 6(3),179-188. https://doi.org/10.1080/15602210600952241

Mak, V., March, G., Clark, A., \& Gilbert, A. (2013). Australian intern pharmacists' perceived preparedness for practice and their expectations and experiences of the internship year and future career intentions. Integrated Pharmacy Research and Practice, 2, 25-34. https://doi.org/10.2147/IPRP.S50387

Marriott, J., Taylor, S., Simpson, M., Bull, R., Galbraith, K., Howarth, H., Leversha, A., Best, D., \& Rose, M. (2005). Australian national strategy for pharmacy preceptor education and support. Australian Journal of Rural Health, 13, 83-90. https://doi.org/ 10.1111/j.1440-1854.2005.00659.x

May, R.M. (1993). Barriers to pharmaceutical care in acute care setting. American Journal of Hospital Pharmacy, 50, 1608-1611. https://doi.org/10.1093/ajhp/50.8.1608

McDonough, R.P., Rovers, J.P., \& Currie, J.D. (1998). Obstacles to the implementation of pharmaceutical care in the community setting. The Journal of the American Pharmacists Association, 38, 87-95. https://doi.org/10.1016/S1086-5802(16)30296-0

McElhaney, A., \& Weber, R. (2014). Role of pharmacy residency training in career planning: A student's perspective. Hospital Pharmacy, 49(11), 1074-1154. https://doi.org/10.1310/ hpj4911-1074

McGrath, S., Snyder, M., Dueñas, G., Pringle, J., Smith, R., \& McGivney, M. (2010). Physician perceptions of pharmacistprovided medication therapy management: A qualitative analysis. Journal of the American Pharmacists Association, 50(1), 67-71. https://doi.org/10.1331/JAPhA.2010.08186

Ngorsuraches, S., \& Li, S.C. (2006). Thai pharmacists understanding, attitudes, and perceived barriers related to providing pharmaceutical care. The American Journal of HealthSystem Pharmacy, 63(21), 2144-2150. https://doi.org/10.2146/ aihp060054

O'Sullivan, T., Sy, E., \& Bacci, J. (2017). A qualitative study designed to build an experiential education curriculum for practice-ready community pharmacy-bound students. American Journal of Pharmaceutical Education, 81(10), 6055. https://doi.org/10.5688/ ajpe6055

Owen, S., Ryan, G., Woulfe, J., Mckauge, L., \& Stupans, I. (2011) Collaborative development of an online pharmacy experiential learning database. Australasian Journal of Educational Technology, 27, 1069-1081. https://doi.org/10.14742/ajet.904

Radigan, J. (2009). The role of internships in higher education (online). Available at: https://www.semanticscholar.org/paper/ THE-ROLE-OF-I-TER-SHIPS-I-HIGHER-EDUCATIO-Radigan/ 8e60410eeadd80aa856666e2e9f147505c492b5f

Rahim, N., \& Nesar, S. (2012). Pharmacy undergraduate students' attitude toward pharmaceutical care in Pakistan. International Journal of Pharmacy and Pharmaceutical Sciences, 4(4), 113-116.
Roberts, A.S., Benrimoj, S.I., Chen, T.F., Williams, K.A., \& Aslani P. (2008). Practice change in community pharmacy: quantification of facilitators. Annal of Pharmacotherapy, 42(6), 861-868. https:// doi.org/10.1345/aph.1K617

Robles, Y. R. (2009). Measuring the impact of new courses in the revised pharmacy curriculum. Journal of the Philippine Pharmacists Association, 2(1), 60

Rodger, S., Webb, G., Devitt, L., Gilbert, J., Wrightson, P., \& Mcmeeken, J. (2008). Clinical education and practice placements in the allied health professions: An international perspective. Journal of Allied Health, 37, 53-62

Stewart, A., Buckner, I., \& Wildfong, P. (2011). A shared assignment to integrate pharmaceutics and pharmacy practice course concepts. American Journal of Pharmaceutical Education, 75(3), 44. https://doi.org/10.5688/ajpe75344

Stupans, I., Mckauge, L., \& Owen, S. (2011). Indicators of a quality clinical placement in pharmacy: Stakeholder perspectives. Journal of Pharmacy Practice and Research, 41, 118-121. https://doi.org/ 10.1002/j.2055-2335.2011.tb00677.x

Toklu, H.Z., \& Hussain, A. (2013). The changing face of pharmacy practice and the need for a new model of pharmacy education. Journal of Young Pharmacists, 5, 38-40. http://dx.doi.org/10.1016/ j.jyp.2012.09.001

Tsega, B., Bhagavathula, A.S., Sarkar, B.R., Melaku, T., \& Shewamene, Z. (2015). Impact of clerkship attachments on students' attitude toward pharmaceutical care in Ethiopia. Advances in Medical Education and Practice, 6, 385-391. https:// doi.org/10.2147/AMEP.S80802

Udeogaranya, P.O., Ukwe, C.V., \& Ekwunife, O.I. (2009). Assessment of attitudes of University of Nigeria pharmacy students toward pharmaceutical care. Pharmacy Practice (Granada), 7(3), 145-149

Uema, S.A., Vega, E.M., Armando, P.D., \& Fontana, D. (2008). Barriers to pharmaceutical care in Argentina. Pharmacy World and Science, 30(3), 211-215. https://doi.org/10.1007/ s11096-007-9167-2

Wallman, A. (2010). Pharmacy internship: Students' learning in a professional practice setting (pp. 1-79). Uppsala University, Sweden (online). Available at: http://uu.diva-portal.org/smash/ get/diva2:293235/FULLTEXT01

WHO [World Health Organisation]. (2007). The role of education in the rational use of medicines.' International Network of Rational Drug Use. WHO: Regional Office for South-East Asia (online) Available at: http://origin.searo.who.int/entity/world_health_day/ media/2011/meetings sea drugs 157.pdf

Young, S., Vos, S.S., Cantrell, M., \& Shaw, R. (2014). Factors associated with students' perception of preceptor excellence. American Journal of Pharmaceutical Education, 78(3), 53. https:// doi.org/10.5688/ajpe78353 